\section{ASSOCIATION OF ORGANOPHOSPHATES EXPOSURE AND SUICIDE}

L London. School of Public Health and Family Medicine, University of Cape Town, South Africa

\subsection{6/oemed-2018-ICOHabstracts.1335}

Introduction Exposure to Organophosphate pesticides (OPs) affects neurotransmitter function in the brain. Changes in serotonin function can result in mood swings, depression, irritability and anger. OP exposure may therefore increase suicide risk by increasing impulsivity and/or depression.

Methods To evaluate whether long-term exposure to OPs is associated with increased risk for attempted suicide and whether increasing levels of exposure are associated with increasing risk of attempting suicide, a case-control study compared 200 adult patients admitted to two teaching hospitals in the Western Cape with a diagnosis of attempted suicide (cases) to 200 age- and gender-matched control patients admitted for unrelated conditions. Exposure assessment was based on (a) work and environmental history; (b) quantification of $\mathrm{OP}$ metabolites in hair. Other measures include a 12-item Aggression Questionnaire, the Barratt Impulsiveness Scale and the Centre for Epidemiologic Studies Depression Scale (CESD-D). Results Of the case and controls, $89 \%$ and $82 \%$, respectively reported a history of occupational pesticide exposure and $12 \%$ and $13 \%$ reported a history of environmental pesticide exposure. There were significant associations $(\mathrm{p}<0.001)$ between being a case and high scores for depression, aggression, impulsivity and AUDIT. There was no association with a history of occupational or environmental exposure to OPs. Hair samples were harvested from only $24 \%$ of cases and controls. Preliminary analysis of hair metabolites did not confirm any association between $\mathrm{OP}$ exposure and suicide attempts.

Discussion Psychological correlates of suicide attempt were consistent with the literature. The absence of any associations with environmental and/or occupational exposures may result from exposure misclassification. Participants were reluctant to give hair samples and this was aggravated by frequent use of synthetic hair braids in women and shaven scalps in men. Low return on hair samples in this population reduced the power to detect associations.

\section{$1659 \mathrm{~g}$ OCCUPATIONAL EXPOSURE ASSESSMENT TO PESTICIDES OF BANANA WORKERS IN THE FRENCH WEST INDIES AND HEALTH RISKS ASSOCIATED TO THEIR ACTIVITIES - MATPHYTO PROJECT}

Mounia El Yamani. Santé publique France, Direction Santé Travail, St Maurice, France

\subsection{6/oemed-2018-ICOHabstracts. 1336}

Introduction The French West Indies are in the tropical zone, which favours the appearance of many pests and plant diseases, but also a significant development of weeds. All these reasons make the use of plant protection products (PPPs) very important which involves a potential high occupational exposure to PPPs by the farm workers.

Method The Matphyto-Antilles project consists on constructing retrospective occupational exposure indicators for PPPs for farm workers and to identify global health effects due to this exposure. A crop exposure matrix (CEM) specific to banana has been built. This CEM lists the use of PPPs on bananas in the two French islands: Guadeloupe and Martinique. Over the last 50 years, the chemical families and/or active substances used on this crop have been identified and 3 exposure indicators have been assigned: a probability, a frequency and an intensity of use. Data of the banana CEM was matched up with the data provided on a specific agricultural census of the Antillean population over the four available years (1981, 1989, 2000 and 2010). Simultaneously a toxicological database listing all the health effects of PPPs authorised in France since 1960 has been established following a methodology based on the toxicity reference values.

Results By matching these different databases, numerous occupational exposure indicators were produced such as the number of farm workers exposed over time and a breakdown by gender, chemical family, substances. The main used PPPs were also linked to health effects including carcinogenicity and endocrine disruption. Our results are useful to implement increased security measures and preventive actions.

\section{9h NANO PESTICIDES ENTERING THE MARKET: NEW RISKS FROM ANCIENT CHEMICALS? THE ROLE OF THE SKIN ROUTE}

F Larese Filon. Institution: Unit of Occupational Medicine, Dept. of Medical Sciences, University of Trieste (Italy)

\subsection{6/oemed-2018-ICOHabstracts. 1337}

Introduction In recent years, nano-based pesticides formulation are developing with the aim to obtain a product that can release the active ingredients only in contact with the target, prolong the effective duration and reduce the dispersion of chemicals in the environment. Big efforts are spend to develop products that can enter in the market, but concern is rising about safety measures to adopt during usage. United States Environmental Protection Agency and European Commission are enacted rules on the management and usage of nano pesticides. Nano formulations can be more active on pests because of the enhancement of penetration, but for the same reason they can penetrate easily into human body mainly through skin route.

Methods a web base survey on pesticides in nano-form tested was done, reviewing scientific literature, technical data and patents on new pesticides formulations with the aim to find information about safety profile comparison between traditional and nano-form.

Results literature is focusing mainly on advantages of nano pesticides in term of reduction of active ingredient to be used in association with less use of chemical agents to disperse it. Very few are data on comparative toxicity on cells line between nano and traditional formulations, showing mainly a lower toxicity for the first one. No animal or human data are available in literature in our best knowledge that compares toxicity between nano and traditional formulation.

Due to high surface/mass ratio nano formulations can be more active on the target but for the same reason can enter quickly into human body via skin contact and inhalation route.

Discussions nano pesticides can offer many advantages from the theoretical point of view but their use need to be evaluated considering the higher permeation into human body that they can have, mainly through the skin route. 